\title{
A atualidade do “hoje" em Dt 26,16-19
}

\author{
The actuality of the "today" in Deut 26: 16-19
}

LeONARDo AgOstini FeRnANDES ${ }^{a}$

\section{Resumo}

Dt 26,16-19 possui um vocabulário específico e determinante, próprio do livro de Deuteronômio. Por isso, pode-se admitir, em particular, a sua capacidade de síntese do conjunto de leis contido em Dt 12-26*. A obediência a YHWH não se faz pela força da lei, mas pela força do amor que está na base da eleição do "novo Israel". Este estudo está estruturado em quatro pontos: 1) Contexto histórico-literário, pelo qual, na medida do possível, busca-se situar o texto na dinâmica do livro; 2) Texto segmentado e notas de crítica, pelos quais se propõe uma tradução, a apresentação e a "solução" para certos problemas; 3) Organização do texto, a fim de favorecer a sua compreensão ad intra do livro de Deuteronômio; 4) Breve comentário aos versículos. Por meio de uma abordagem sincrônica, objetiva-se propor e alcançar uma atualização que atenda à proposta presente no título desse artigo.

Palavras-chave: Livro de Deuteronômio. "Hoje". Obediência. Torah. Atualização da mensagem.

\section{Abstract}

Deut 26:16-19 has a specific and determinant vocabulary proper of Deuteronomy's book. For this reason, it is possible to admit, in particular, its ability to synthesize the set of laws contained in Deut 12-26*. The obedience to YHWH is not done by the force of the law, but by the force of the love that is at the basis "new Israel" election. This study is structured within four points: 1) Historical-literary context, whereby, as much as possible, we seek to situate the text in the dynamics of the book; 2) Segmented texts and critical notes, for which a translation, presentation and "solution" for determined problems are proposed; 3) Organization of the text in order to favor its ad intra comprehension of Deuteronomy's book; 4) Brief commentary on

\footnotetext{
a Pontifícia Universidade Católica do Rio de Janeiro (PUC-Rio), Rio de Janeiro, RJ, Brasil. Doutor em Teologia, e-mail: laf2007@puc-rio.br
} 
the verses. Through a synchronic approach, the aim is to propose and achieve an update that meets the proposal in the title of this paper.

Keywords: Book of Deuteronomy. "Today". Obedience. Torah. Message update.

\section{Introdução}

Desejo iniciar com duas perguntas: Em que sentido um livro bíblico, ou um de seus textos, em particular do Antigo Testamento, pode ser considerado relevante para o tempo atual e para quem se diz praticante da Sagrada Escritura e não mero ouvinte (Tg 1,22)? Em que sentido, no caso particular do livro de Deuteronômio, os seus ensinamentos e legislação podem ser determinantes, ainda “hoje”, para quem almeja alcançar a realização na sua vida, admitindo que é necessário colocar em prática os decretos, os juízos e as ordens de YHWH?

O livro de Deuteronômio, em grande parte, é legislativo, mas uma leitura atenta revela que é muito mais do que um conjunto de leis (Dt 12-26*), é uma boa nova pregada e carregada de reflexão sobre o valor da lei para a vida do povo que busca ser feliz. Para isto, é preciso conhecer e cumprir a vontade de $\mathrm{YHWH}$, não por um caminho simplesmente pautado na lei, mas trilhado na experiência da sua presença e do seu amor incondicional, pois YHWH escolheu livremente o seu povo e tomou posse dele por puro amor (Dt 7) ${ }^{1}$. Este amor é a força da legislação contida no livro e é a motivação para a compreensão do sentido do "hoje”, como graça e salvação.

\footnotetext{
1 "El amor de Dios, solemnemente proclamado al principio de la obra y repetidas veces inculcado a lo largo de la misma, encarna el valor esencial, al que se han de conformar todas las otras leyes. Esta enseñanza recibirá el respaldo definitivo de Jesús de Nazaret: Si me amáis, obedeceréis mis mandamientos (Jn 14,15). Entendido de este modo, el libro del Deuteronomio se convierte, ciertamente, en 'una prefiguración del Evangelio' (San Jerónimo) y el cristiano de hoy estará en lo cierto si lo acoge con veneración, procurando extraer de él aquellos valores permanentes, capaces de iluminar y alimentar su vida como creyente" (GÁRCIA LÓPEZ, 1992, p. 9).
} 


\section{Contexto histórico-literário}

Segundo a narrativa contida na Torah, Ex 19,1 afirma que os libertos, guiados por Moisés, chegaram ao monte Sinai no terceiro mês depois da sua saída do Egito. No Sinai, ficaram por quase um ano e, após celebrarem a aliança e receberem a legislação, retomaram a marcha pelo deserto rumo à terra prometida $(\mathrm{Nm} 10,11)$. O povo que saiu do Egito não é o mesmo que deixou o Sinai, pois foi constituído uma propriedade particular de YHWH (Ex 19,3-7). Este povo se preparou para deixar o Sinai de forma organizada, segundo as suas tribos e estandartes, a fim de marchar como um numeroso exército, pronto para tomar posse de Canaã ( $\mathrm{Nm}$ 1,1-10,10).

Contudo, esse povo experimentará a "ira de YHWH" por causa da sua dura cerviz; os que saíram do Egito, morreram no deserto, vítimas da desobediência que praticaram ( $\mathrm{Nm} \mathrm{14,22-23;} \mathrm{Dt} \mathrm{2,14-16).} \mathrm{No} \mathrm{seu} \mathrm{lugar,} \mathrm{porém,}$ nasceu um "novo Israel", destinado a entrar, conquistar e receber a terra em herança $(\mathrm{Nm} 26,53.65)$. É para este "novo Israel” que Moisés discursa no livro de Deuteronômio, a fim de lhe inculcar a Torah (Dt 1,1.5). A aliança, selada no Sinai e violada pela antiga geração, foi renovada com a nova geração, antes desta atravessar o Jordão e de tomar posse da Terra² ${ }^{2}$.

O contexto geográfico desse livro situa a fala de Moisés nas estepes de Moab (Nm 36,13; Dt 1,5; 34,1.5-6.8), local onde ocorre a renovação do pacto do Sinai e pode ser denominada: "aliança de Moab"3. Assim, o que a aliança do Sinai foi para os libertos do Egito (Ex 20,22-23,33), a aliança celebrada em Moab o será para o "novo Israel”. Josué, sucessor de Moisés (Dt 34,9), será o eleito que guiará e fará o "novo Israel" atravessar o Jordão e entrar na terra de Canaã (Js 1,1-18). No fim de sua vida, a aliança será novamente renovada (Js 24,1-28).

\footnotetext{
2 Muitas são as teorias que querem explicar o surgimento, a entrada e a tomada da terra de Canaã pelos filhos de Israel. Sobre o assunto: DA SILVA, 2003, p. 43-87; KESSLER, 2009, p. 47-66; MAZZINGHI, 2017, p. 37-47.

${ }^{3}$ Segundo Jean-Pierre Sonnet (2018, p. 10): "Moisés acrescenta um elemento que introduz um enigma em seu discurso. Percebe-se, claramente, que o pacto em Moab é concluído não apenas com a geração para a qual se dirige, mas também "com aquela que não está conosco" (Dt 29,14). Assim como a aliança do Horeb, a aliança de Moab é "excessiva": ela é produzida igualmente para beneficiar os destinatários que não estão empiricamente presentes (Dt 29,4-4)".
} 
Diante desse quadro sintético, Dt 26,16-19 é um texto importante, pois contém a exortação que conclui o chamado "Código Deuteronômico" (Dt 1226) 4 , admitido como o centro ou o ponto de partida que originou o livro de Deuteronômio. Este teve e certamente passou por várias fases redacionais até chegar à sua forma final entre os séculos V-IV a.C5. Então, se está diante de uma "palavra final" sobre um código legislativo que deu origem ao processo de datação da hipótese dos documentos-fontes com De Wette que o situou nos tempos de Josias (2Rs 22-23) ${ }^{6}$. A pesquisa moderna, porém, aponta para outras fases redacionais ocorridas no período persa?

Dt 26,16-19, do ponto de vista do contexto próximo anterior, integra a unidade Dt 25,17-26,19. Nesta, encontram-se duas confissões litúrgicas (Dt 25,17-26,15) e a recapitulação da aliança (Dt 26,16-19). Nota-se, porém, uma clara alusão a Dt 12,1 que começa a expor o código legislativo e a Dt 5,1 que inicia o segundo discurso de Moisés (Dt 4,45-28,68) ${ }^{8}$. A terminologia

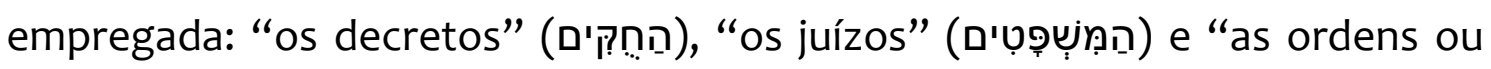
ordenanças" (הַפַּצוֹת), atesta, igualmente, a relação temática com a solene declaração contida em Dt 6,4. Nesse amplo contexto, Dt 26,16-19 termina,

\footnotetext{
${ }^{4}$ Para Azcárate (2009, p. 14-15): "Algunos autores plantean una estructura concéntrica en la que el Código Deuteronómico (Dt 12-26) ocupa un lugar central: A. Marco exterior: Una mirada retrospectiva (Dt 1-3); B. Marco interior: El gran discurso (Dt 4-11); C. Núcleo central: Las estipulaciones de la alianza (Dt 12-26); $B^{\prime}$. Marco interior: La ceremonia de la alianza (Dt 2730); A'. Marco exterior: Una mirada prospectiva (Dt 31-34)"

${ }^{5} \mathrm{~A}$ tese tradicional coloca a elaboração do livro entre o final do século VIII a.C. e a metade do século VI a.C. (VON RAD, 1979, p. 26-34; HOPPE, 1993, p. 9-10; CLIFFORD, 1995, p. 5-10).

${ }^{6}$ Admite-se a relação de Dt 12-26 com a pessoa e o reinado de Josias narrado em 2Rs 22-23, diferente, porém, são as interpretações dessa relação (THOMPSON, 1974, 57-66; BRAULIK, 1987, 12-17; MANN, 1995, p. 4-8; WRIGHT, 1996, p. 6-8; LOHFINK, 1990, p. 252-254; BRUEGGEMANN, 2001, p. 19-20; MILLER, 2008, p. 13-15; RÖMER, 2008, p. 55-61; AZCÁRATE，2009, p. 21-24; PAGANINI, 2011, p. 21-24; PAPOLA, 2011, p. 26-32).

${ }^{7}$ A proposta de Thomas Römer (2008, p. 51-90) prevê, pelo menos, três fases: pré-exílica, exílica e pós-exílica. Esta última é fundamental pois acontece durante o período persa, tempo decisivo para a elaboração e para a feitura final de vários livros bíblicos.

8 "Esta sección conformaría el Deuteronomio primitivo de época de Josías o incluso quizá Ezequías. En su configuración actual aparece como el segundo discurso, que también se remonta hasta el monte Horeb, y que sirve de marco al código deuteronómico (Dt 12,11-21,15), discutiéndose si éste es anterior a Josías y procedente del reino del Norte o es exclusivamente de la época de Josías" (AZCÁRATE, 2009, p. 25).
} 
praticamente da mesma forma como esse corpus legislativo começou e cria uma espécie de moldura baseada na temática e na terminologia empregada ${ }^{9}$.

Do ponto de vista posterior, Dt 26,16-19 prepara ou serve de transição para o capítulo que se refere às bênçãos (Dt 28,1-14) e às maldições (Dt 28,1568) que, dentro do pacto, são um elemento indispensável ${ }^{10}$.

Percebe-se, então, a importância de Dt 26,16-19, pois reflete a ratificação do "Código Deuteronômico", pelo qual o povo confirma o seu desejo de concluir a aliança com YHWH e seguir todos os seus mandamentos ${ }^{11}$. Este seguir implica em conhecimento e comportamento, isto é, na ética que aparece em Dt 26,17 sob a frase: "andar em seus caminhos" ${ }^{12}$. Na verdade, este é o centro de todo o projeto de libertação do Egito: amar, servir e temer YHWH. Três ações indispensáveis para se escolher o caminho da vida e se evitar o caminho que conduz à morte (Dt 30,19).

\section{Texto e notas de crítica}

\begin{tabular}{|l|l|l|}
\hline Hoje mesmo, & $16 a$ & \\
\hline
\end{tabular}

\footnotetext{
9 No segundo discurso de Moisés, nota-se que a aliança segue a forma dos tratados de vassalagem (BRAULIK, 1987, p. 9.84; PAGANINI, 2011, p. 31.366-367; PAPOLA, 2011, p. 17-18). Há quem considere Dt 26,1-19 como uma unidade que conclui Dt 12-26 (PAPOLA, 2011, p. 281.287/ LUNDBOM, 2013, p. 734); ou uma unidade maior: Dt 4,41-26,19 (MAXWELL, 1987, p. 288); Dt 4,44-28,68 sobre o qual Dt 26,1-28,68 seria a conclusão de todo o segundo discurso de Moisés (CAIRNS, 1992, p. 2-3; p. 227-249); Dt 5,1-26,15 (THOMPSON, 1974, p. 258).

10 Uma cerimônia podia concluir e ratificar o pacto (GÁRCIA LÓPEZ, 1992, p. 112; MILLER, 2008, p. 199-207).

${ }^{11}$ Ao se considerar a forma final do livro, é possível entrever uma estrutura simétrica, na qual Dt 26,16-19 ocupa um papel central. Eis a proposta de Christensen (2002, p. 644): "A: Blessing and curse in a covenant renewal under Moses (11:26-28); B: Blessing and curse in a covenant renewal at Shechem (11,29-32); X: Mutual commitments made between YHWH and Israel $(\mathbf{2 6 , 1 6 -}$ 19); $B^{\prime}$ : Blessing and curse in a covenant renewal at Shechem (27,1-26); $A^{\prime}:$ Blessing and curse in a covenant renewal under Moses (28,1-69)". Há quem tenha ido mais além, admitindo que Dt 26,16-19 serviria para ligar Dt 6-11 e 12-26 com Dt 28 (NELSON, 2002, p. 311).

12 Esta proposta faz parte dos conselhos que Jetro deu a Moisés (Ex 18,20) e retorna em Dt 5,33; 6,$7 ; 8,6 ; 10,12 ; 11,19.22 ; 13,6 ; 19,9 ; 26,17 ; 28,9 ; 30,16$.
} 


\begin{tabular}{|c|c|c|}
\hline $\begin{array}{l}\text { YHWH, teu Deus, te ordena praticar } \\
\text { esses }^{13} \text { decretos e juízos. }\end{array}$ & $16 b$ & 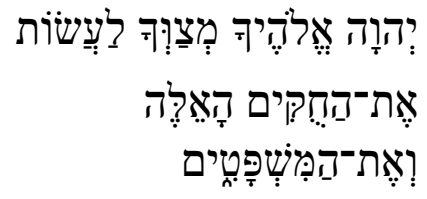 \\
\hline Observarás & $16 c$ & רוֹשַָׁחרְתָּ \\
\hline e os praticarás, & $16 d$ & וְעָעשׁיָת אוֹתָם \\
\hline $\begin{array}{l}\text { com todo o teu coração } \\
\text { e com todo o teu ânimo }{ }^{14} \text {; }\end{array}$ & $16 e$ & 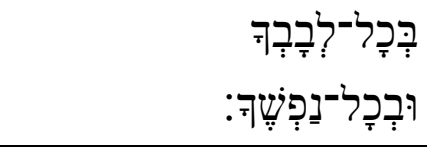 \\
\hline A YHWH, hoje, declararás ${ }^{15}$ : & $17 \mathrm{a}$ & 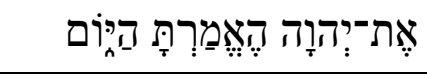 \\
\hline "Deus, para ti, há de ser"16, & $17 \mathrm{~b}$ & לְהְיוֹת לְף לְאלוּהים \\
\hline para andar no caminho dele, & $17 \mathrm{c}$ & 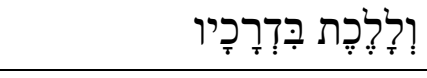 \\
\hline $\begin{array}{l}\text { para observar os seus decretos, } \\
\text { as suas ordens e os seus juízos }{ }^{17} \text {, }\end{array}$ & $17 d$ & 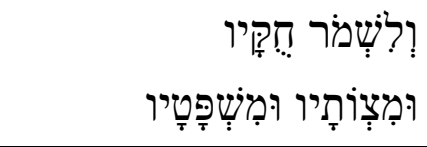 \\
\hline e escutar a sua voz". & $17 e$ & 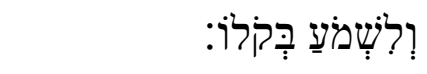 \\
\hline Então, hoje, YHWH te declarará18: & $18 \mathrm{a}$ & 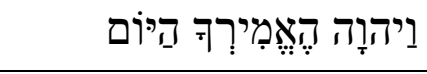 \\
\hline Para ser para ele por povo peculiar, & $18 b$ & לִהְיוֹת לוֹ רְעַם סְגְלְּה \\
\hline conforme falou para ti ${ }^{19}$ & $18 \mathrm{c}$ & 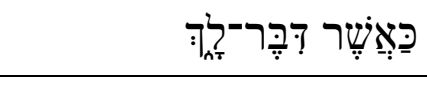 \\
\hline
\end{tabular}

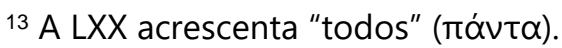

14 É comum a tradução: "de todo o teu coração e de toda a tua alma". A opção está justificada no comentário.

${ }^{15}$ A dificuldade textual é sentida de várias maneiras. Por exemplo: "A exata tradução do v. 17

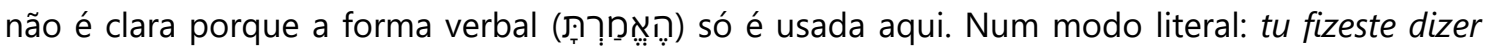
ao Senhor, mas o significado é deixar que alguém diga ou aceitar o que alguém disse" (CLIFFORD, 1995, p. 133). É possível ler este hápax como um intensivo e não um causativo (GKC $\S 53 d)$ : "tu proclamaste solenemente" (LUNDBOM, 2013, p. 734).

${ }^{16}$ Os vv. 17-19 contêm vários verbos no infinitivo construto precedidos de preposição. Traduzilos pelo futuro é uma opção possível. A questão é se as ações, de fato, serão cumpridas pelo povo. Por isso, preferiu-se manter a tradução dos verbos no infinitivo. Em cada declaração, o sujeito do primeiro infinitivo é quem fala. Moisés é quem, como mediador, faz falar o povo e YHWH, colocando-os em relação. $\mathrm{O}$ uso do verbo no infinitivo seria um recurso gramatical exatamente para evidenciar o papel de Moisés como mediador (NELSON, 2002, 311).

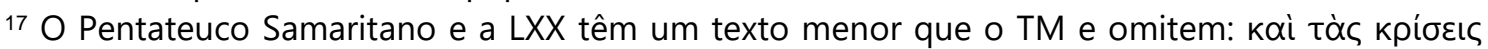
aủtoû (Dt 8,11).

${ }^{18}$ A LXX, como no v. 17, teve dificuldade para traduzir o hebraico e manteve a opção pelo verbo

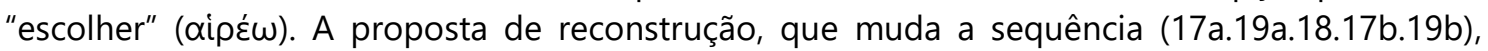
melhora o texto, mas é mera conjectura (CHRISTENSEN, 2002, p. 644; PAPOLA, 2011, p. 287; LUNDBOM, 2013, p. 734). 


\begin{tabular}{|c|c|c|}
\hline e para observar todas as suas ordens. & $18 d$ & 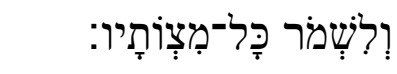 \\
\hline $\begin{array}{l}\text { O altíssimo }{ }^{20} \text { te colocará } \\
\text { sobre todas as gentes que fez, } \\
\text { para o louvor, para o nome e para o } \\
\text { esplendor, }\end{array}$ & $19 a$ & 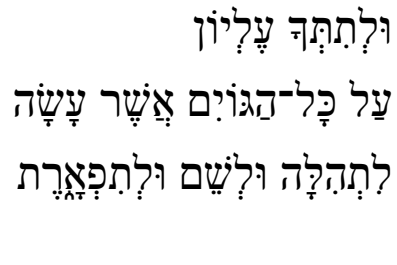 \\
\hline $\begin{array}{l}\text { e tu hás de ser um povo santo } \\
\text { para YHWH teu Deus, }\end{array}$ & $19 c$ & 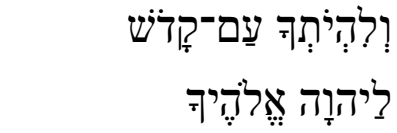 \\
\hline conforme falou. & $19 d$ & 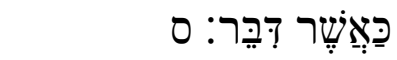 \\
\hline
\end{tabular}

\section{Organização do texto}

Dois tipos de locução temporal no livro de Deuteronômio chamam a atenção: a) "hoje mesmo" (הַיוֹם הַזְּה), que ocorre cinco vezes (Dt 2,25; 5,24;

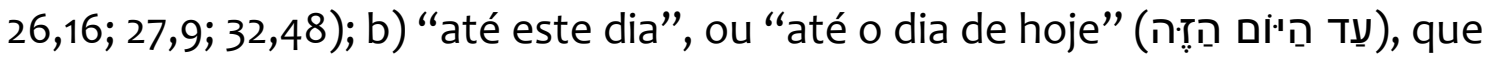
ocorre seis vezes (Dt 2,22; 3,14; 10,8; 11,4; 29,3; 34,6). Um dado é relevante: a locução “hoje mesmo", no "Código Deuteronômico" (Dt 12-26), ocorre apenas em Dt 26,16. Diante disso, uma questão se impõe: Que tipo de mudança o uso da locução, "hoje mesmo" (Dt 26,16), intenta fazer ao lado das duas vezes em que ocorre o termo “hoje" (Dt 26,17.18)?21

${ }^{19}$ A LXX ${ }^{(B)}$ omite "para ti", criando uma relação com o v. 19d. Já o Targum, ao invés de "para ti", traz "para vós".

${ }^{20}$ A opção de 'elyôn por sujeito da frase é justificável pelo uso da preposição 'al que já permite entender que o povo, por sua relação com $\mathrm{YHWH}$, está sendo colocado acima dos outros povos. O termo 'elyôn é aplicado, geralmente, aos deuses, indica quem é o mais alto no ranque ( $\mathrm{G} n$ 14,18-22; SI 7,17; 46,4; 82,6). Não é usual aplicado ao povo, "mas este é o povo que é 'elyôn pela virtude da gratuita eleição de Deus. Esta primeira aliança não foi feita entre YHWH e o rei, mas entre YHWH e o povo" (CAIRNS, 1992, p. 228).

A conclusão sobre essas dificuldades pode ser facilitada ao se admitir que o estilo retórico é a marca característica de Dt 26,16-19. Algo já considerado relevante e pertinente há décadas (LOHFINK, 1968, p. 119).

${ }^{21}$ A solução apresentada por Von $\operatorname{Rad}(1979,179)$ foi a de considerar o v. 16 como sendo a conclusão parenética de tudo o que iniciou em Dt 12,1 e, com isso, desvinculou os vv. 17-19 que passam a ser entendidos como a estipulação de um contrato, no qual as partes fazem suas declarações e confirmam a aliança pactuada. Do ponto de vista cultual, indicaria uma intensa mudança litúrgica, pois o modo como o povo se compromete com $\mathrm{YHWH}$, pela aliança, cria uma profunda identidade entre ambos e os feitos salvíficos são atualizados (GÁRCIA LÓPEZ, 1992, p. 113; HOPPE, 1993, p. 114-115; CLIFFORD, 1995, p. 133; BRUEGGEMANN, 2001, p. 248). 
Moisés, pela narrativa, é uma figura que medeia as partes e suas declarações, ele usa o "hoje" dos seus ouvintes, a fim de resumir, reapresentar e repropor a aliança aos que nasceram no deserto e que estão para entrar na terra prometida ${ }^{22}$.

O "hoje mesmo" (v. 16a) e o "hoje" (v. 17a.18a) atestam a insistência de quem fala: Moisés; e a quem se fala: o "novo Israel", geração que sucedeu àquela que saiu do Egito. Se, por um lado, reenvia ao "hoje" do mensageiro e dos destinatários, por outro lado, imposta a fala para o ouvinte-leitor real do livro em qualquer época ${ }^{23}$.

As três ocorrências do termo "hoje" ajudam a estruturar Dt 26,16-19, de forma simétrica ${ }^{24}$, e permitem que essa seção conclusiva seja classificada como "fórmula da aliança"25:
A: Passado: Moisés sigila tudo o que falou (v. 16);
B: Declaração dada a YHWH (v. 17);
$\mathrm{B}^{\prime}$ : Declaração dada por YHWH (v. 18);
$A^{\prime}$ : Futuro: Moisés fala dos efeitos (v. 19).

Percebe-se, dessa forma, que existe um motivo para o termo "hoje" não ter sido usado no v. 19, pois este versículo aponta para o futuro que não existe, existirá, na dependência desse "hoje", bem vivido na presença de YHWH pela obediência à aliança, graças ao passado desse "novo Israel” que: 1) não experimentou a saída do Egito; 2) não experimentou a primeira etapa da marcha pelo deserto; 3) mas que experimentou a rebeldia dos seus pais mortos no deserto. Herdeiro das promessas, esse "novo Israel" deve

\footnotetext{
22 "Essa realidade central da aliança é reforçada pela promessa de YHWH de que Israel será sua possessão preciosa e pelo compromisso que Israel tem de andar em seus caminhos, manter seus decretos e obedecê-lo". Há uma ligação direta com Dt 26,16 (WRIGHT, 1996, p. 272).

${ }^{23} \mathrm{Na}$ dinâmica bíblica, as narrativas não se destinam apenas ao ouvinte-leitor real, mas também aos futuros ouvintes-leitores reais de cada época e lugar. Para um exemplo dessa perspectiva: SONNET, 2018, 1-20.

24 "Os três termos clássicos para definir a lei retornam cada um duas vezes, se repetem de modo concatenado e de acordo com o modelo a-b-a-c-b-c: a) os huqqîm (decretos) retornam em Dt 26,16.17; os mišpāțîm (juízos) em Dt 26,16.17; c) os mișwōt (ordens) em Dt 26,17-18 (PAGANINI, 2011, 367).

${ }^{25}$ A classificação deve-se aos elementos constitutivos: o suserano e os vassalos empenham a própria palavra: YHWH aceita ser o Deus de Israel e este aceita ser o seu povo. Chama a atenção que Israel é introduzido como sujeito do discurso e declara no v. 18 que é povo particular de YHWH (MANN, 1995, p. 141; PAPOLA, 2011, p. 287).
} 
aprender a ser diferente da geração precedente para tomar posse da terra prometida, pois, se entrar, é porque YHWH é fiel às suas promessas.

As duas declarações (vv. 17-18) mostram como as partes, que selam a aliança, se comprometem mutuamente ${ }^{26}$. A impostação verbal nesses dois versículos (אמר no hifil qatal, respectivamente na segunda e terceira pessoa do masculino singular) evidencia, sobretudo, o caráter dialogal e bilateral dessa aliança reproposta. Não é uma imposição, mas um mútuo e livre compromisso que vem (re)estabelecido.

Na base da aliança, estão os compromissos recíprocos: três, por parte do povo (Dt 26,17), e três, por parte de YHWH (Dt 26,18-19). É curioso que, nesse pacto, a parte mais fraca se comprometa primeiro e depois a parte mais forte. Tudo, porém, aparece chancelado pela palavra final de YHWH: "conforme falou" (v. 19d). Por ser o povo escolhido por YHWH, o único, uno e verdadeiro Deus (Dt 6,4; 7,6-8; 10,12-14), o "novo Israel” passa a ser elevado em sua posição em relação aos demais povos.

\section{Breve comentário}

v. 16ab: Hoje mesmo, YHWH, teu Deus, te ordena praticar esses decretos e juízos.

A exortação de Moisés, que acompanha o conteúdo iniciado em Dt 12,1, pela aceitação de todo o corpus legislativo contido em Dt 12-26*, precisa ser, cumprida "hoje mesmo" 27 , isto é, no momento em que os destinatários a

\footnotetext{
26 "Cada declaração tem quatro cláusulas, das quais somente uma expressa as obrigações assumidas pela parte declarante, enquanto as outras três afirmam as obrigações da contraparte. O Senhor declara que ele será o Deus de Israel e exige que este o sirva com três diferentes formulações. Israel declara que obedecerá aos mandamentos do Senhor com as suas três condições: sendo sua particular propriedade (cf. Dt 7,6), sendo exaltado acima de todas as nações e sendo santos, ou seja, separados" (CLIFFORD, 1995, p. 133-134). É a base da fórmula da aliança bilateral do Sinai (Ex 6,7; Jr 31,33; Ez 36,28) entre YHWH e Israel (VON RAD, 1979, p. 180).

27 O termo definido por artigo, traduzido por um advérbio temporal: "hoje", ou por um substantivo: "o dia" (הַ) vezes só no "Código Deuteronômico" (Dt 12,8; 13,19; 15,5; 19,9; 20,3; 26,3.16.17.18). Pela narrativa, o "novo Israel", que está ouvindo a voz de YHWH pela mediação de Moisés, deve fazer a sua escolha e esta não pode ser adiada para outro dia, precisa ser feita no "hoje" da instrução que recebe antes de entrar em Canaã (DEVRIES, 1974, p. 301-316; CAIRNS, 1992, p. 227).
} 
ouvem e a aceitam. Tal cumprimento começa no "hoje" da livre adesão de cada pessoa em seu íntimo.

Esse "hoje mesmo" é perene e não pode ser esquecido porque, por sua vez, eles se tornam responsáveis pela compreensão do que estão ouvindo e se tornam responsáveis pelo que deverão transmitir para as futuras gerações, pois Moisés está para morrer (Dt 34). O ato de assumir o compromisso comporta, também, o firme propósito de formar a nova geração para que não se afaste da aliança, razão pela qual será renovada (Js 24,1-28) 28 . Este afastamento, pela narrativa, se verificará no livro de Juízes que inicia a série de acontecimentos punitivos que confirmam o que está previsto no livro de Deuteronômio. Jz 2,1-23 sintetiza bem essa lógica.

A dinâmica subjacente ao "hoje mesmo" é tão forte que se deve atuar na vida cotidiana na terra que estão para conquistar. Não é à toa que vibra como uma ação litúrgica, momento propício para se renovar a aliança sempre que for necessária, particularmente nos momentos em que se comparecia a um santuário local a fim de cumprir um ato cultual, comprovando os vínculos do presente — "hoje mesmo" — com o passado (Dt 26,1-15) 29 .

A declaração — "YHWH, teu Deus" - é marcante no livro de Deuteronômio ${ }^{30}$. Por essa, indica-se a relação pessoal do povo com YHWH. A base dessa relação é a aliança, pela qual o povo passa a pertencer a YHWH e "vice-versa". Na voz de Moisés, essa declaração não denota apenas a exclusividade do povo em relação a YHWH (Ex 19,3-7), mas evidencia a exclusividade com a qual $\mathrm{YHWH}$ deve ser crido e assumido pelo povo, pois só

\footnotetext{
${ }^{28}$ A figura de Josué, citada em Dt 34,9, condensa a perspectiva obediencial que YHWH espera do seu povo. Esta perspectiva é devidamente retomada em Js 1,1-9 que evidencia a lógica da ação obediencial exigida.

${ }^{29}$ Um particular chama a atenção: no livro de Deuteronômio o termo aliança ocorre vinte e sete vezes, seja na forma absoluta, ou construta, mas só ocorre uma vez no "Código Deuteronômico" em Dt 17,2. Esta citação é central, de modo que existem treze citações antes (Dt 4,13.23.31; $5,2.3 ; 7,2.9 .12 ; 8,18 ; 9,9.11 .15 ; 10,8$ ) e treze citações depois (Dt 28,69[2x]; 29,8.11.13.20.24; $31,9.16 .20 .25 .26 ; 33,9)$.

30 No livro de Deuteronômio existem duzentas e doze ocorrências de "YHWH, teu Deus". Ao lado dessa, encontram-se quarenta ocorrências de "YHWH, vosso Deus" e onze vezes na forma construta "YHWH, Deus de". Esta breve estatística permite constatar a força do estilo repetitivo e retórico por meio de frases e construções estereotipadas que objetivam informar e convencer os destinatários (ASCÁRATE, 2009, p. 10-11).
} 
ele é Deus (Dt 4,35.39) e é o único libertador do Egito (Dt 5,6). É dessa declaração que a seguinte determinação recebe toda a sua força, pois só o Deus único $(D t 6,4)$ pode dizer: te ordena praticar esses decretos e juízos.

Os termos, "decretos" e "juízos", são pertinentes no livro de Deuteronômio. Para além das vinte e uma ocorrências do termo "decreto" nesse livro, a presença em Dt 12,1 e 26,16 permite afirmar que o alcance do seu conteúdo engloba todo o ensinamento que está entre esses dois limites e o comportamento moral que deriva. O mesmo pode ser dito sobre o termo "juízo" que ocorre trinta e sete vezes no livro e, juntamente com o termo “decreto", emoldura o que se encontra em Dt 12,1-26,15.

Com isso, nota-se a força que reside na passagem de "YHWH, Deus de teus pais" (Dt 12,1) para "YHWH, teu Deus" (Dt 26,16). É a fé e o compromisso que são assumidos e que devem ser recebidos e praticados de geração em geração. Por isso, o caminho legislativo, transmitido à nova geração, reforça a identidade e a pertença do povo a YHWH que o assumiu como sua pessoal e peculiar propriedade.

A ordem que YHWH prescreve, por meio de Moisés, deve ser cumprida na sua totalidade e sem reservas (Dt 12,14; 26,16), pois tem uma finalidade específica: o êxito das ações e a prolongada estadia na terra prometida (Dt 4,40; 6,2). Tudo isso deve ser registrado e permanecer como um testemunho público (Dt 27,3). Bênçãos estão reservadas se houver obediência, mas também maldições são anunciadas se não houver obediência (Dt 11, de certa forma, prepara Dt 28). Vê-se, aqui, que o conhecimento não apenas determina o comportamento, mas incide, inclusive, sobre as consequências que derivam ou não da obediência às ordens recebidas.

v. 16cd: Observarás e os praticarás com todo o teu coração e com todo o teu ânimo.

Dt 16,12 e 26,16 conservam os dois verbos em sequência: observar e praticar, mas só aqui se encontram ao lado das locuções "com todo o teu coração" e "com todo o teu ânimo", ocupando uma posição central na dinâmica do livro: três vezes antes (Dt 4,29; 6,5; 10,12) e três vezes depois (Dt 30,2.6.10) de Dt 26,16. 
Nesta formulação, se entende que cumprir a lei não é uma obrigação formal, mas uma verdadeira prova de amor (Dt 6,5; 10,12; 30,6), ação ápice que exige busca verdadeira e sincera conversão a YHWH (Dt 4,29; 30,2.10) ${ }^{31}$. Essa atitude, se é perfeita, intensa e total, trará benefícios aos que entrarão na terra (Dt 11,13-15).

Entre observar e praticar, pode-se admitir outras duas ações: refletir e assimilar o conteúdo que Moisés está transmitindo. Daí a imagem do "coração" que, segundo a mentalidade semita, é a sede do pensamento e da interioridade do ser humano, e a imagem da "alma" que indica o ser que tem vida $(\operatorname{Gn} 2,7)^{32}$.

Se o pulsar do coração e o respiro mostram que existe vida numa pessoa, juntos intensificam o sentido e o valor das opções e das ações assumidas na aliança. Nota-se, claramente, a relação quase sinonímica entre os verbos "observar" e "praticar" e os substantivos "coração" e "alma".

Essa dinâmica fica bem evidente nos textos paralelos: O rei Josias, ao tomar conhecimento do conteúdo do livro da aliança, encontrado no templo (2Rs 23,3), assumiu, pessoalmente, a aliança com $\mathrm{YHWH:} \mathrm{"com} \mathrm{todo} \mathrm{o}$ coração e com todo o ânimo". No Salmo 119, o orante: declara beato quem é fiel aos ensinamentos de YHWH e o busca com todo o coração (SI 119,2); pede a YHWH inteligência para observar e guardar a sua Torah com todo o coração (SI 119,34); suplica a YHWH com todo o coração e espera ser atendido (SI 119,58); não titubeia diante dos males e calúnias que sofre, mas com todo o coração observa os preceitos de YHWH (SI 119,69); invoca YHWH, com todo o coração, certo de que será respondido (SI 119,145). E Sf 3,14 convida a filha de Jerusalém a se alegrar com todo o coração.

\footnotetext{
${ }^{31} \mathrm{~A}$ força da lei se manifesta não como expressão de algo absoluto, mas enquanto presença do que é absoluto e está na base das relações entre YHWH, que ordena cumprir as leis, e o povo, que se obriga a cumprir essas leis (LOHFINK, 1990, p. 211-261). Percebe-se uma aproximação a essa dinâmica em Jo 13,1-17,26. No contexto da última ceia, Jesus entrega aos seus discípulos o novo mandamento: "Amai-vos como eu vos amei" (Jo 15,12).

32 O termo לְִ לְבְבָ significa: "homem interior", "mente", "vontade", "coração", "alma",

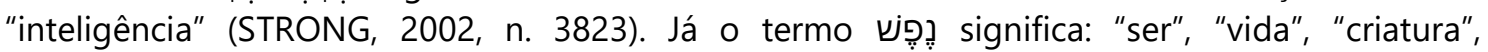
"pessoa", "apetite", "mente", "ser vivo", "desejo", "emoção", "paixão" (STRONG, 2002, n. 5315). 
As duas locuções expressam, pela preposição “com”, a conformidade do povo com a vontade de $\mathrm{YHWH}$; implicam união, afeto e aproximação que se estabelecem entre as partes contraentes, e evidenciam, ainda mais, a bilateralidade da aliança, pela qual se reforçam as relações interpessoais entre YHWH e o seu povo.

v. 17: A YHWH, hoje, declararás: "Deus, para ti, há de ser; e para andar no caminho dele; para observar os seus decretos, as suas ordens e os seus juízos, e escutar a sua voz".

Moisés diz ao povo que este deve declarar a sua pessoal e livre opção por YHWH e aceitá-lo como seu único Deus. Esta ação lembra a resposta que o povo deu a YHWH através de Moisés em Ex 19,8: "Tudo o que YHWH falou, faremos!" A mesma aceitação do povo, ao que disse YHWH, encontra-se em Ex 24,3.7: "Todas as palavras que falou YHWH, faremos" (v. 3); "Tudo o que falou YHWH, faremos e escutaremos" (v. 7). Assim, escutar YHWH é obedecêlo pela prática e pela ação.

$\mathrm{Na}$ força dessa declaração segue o primeiro empenho: "andar no caminho dele"; o que equivale, primeiramente, à escolha do melhor e bom caminho $^{33}$, que é a via do bem, da justiça e da verdade vivida e praticada segundo tudo o que está prescrito em Dt 12-26*. É uma afirmação de fidelidade incondicional e sem reservas. Esta se traduz na obediência ao complexo da aliança que está sendo estabelecida através dos termos: “decretos”, “ordens” e “juízos”. Tal obediência, em síntese, se reduz a ouvir e a obedecer atentamente a voz de YHWH. Isto é uma prova de conhecimento e de renúncia, pois se deduz que não existirá submissão a qualquer outra divindade, visto que YHWH é o "Altíssimo" (עִֶׁלין: v. 19).

É conhecida a formulação da recíproca pertença: “Eu serei o teu Deus e tu serás o meu povo" (SI 95,7; Jr 7,23; 31,33), mas também existe a sua antítese: "não serás meu povo" (Os 1,9; 2,1). Se para YHWH, em relação ao povo, ocorreu uma livre escolha, para este, porém, a percepção e a entrega se deram por meio de uma verdadeira conquista da parte de $\mathrm{YHWH}$.

\footnotetext{
${ }^{33} \mathrm{Em}$ Jr 6,16, YHWH propõe ao povo que reflita e escolha o bom caminho, mas lamenta que não foi ouvido.
} 
A libertação do Egito e a marcha pelo deserto, rumo à terra de Canaã, se apresentam de Ex a Dt como uma história de envolvimento, com seus altos e baixos, como é próprio numa história de amor. YHWH, não apenas se apresenta como forte e dominador, mas como um Deus que deseja conquistar e "ser conquistado" pelo povo que escolheu. Somente no amor isso pode acontecer, porque é a condição indispensável da liberdade no ato da opção por YHWH e pela prática de todas as cláusulas da aliança contraída ${ }^{34}$.

O povo, ao declarar que, “hoje”, escolhe YHWH por seu Deus, está fazendo a sua opção pessoal por uma divindade que não foi buscar, mas que veio livremente ao seu encontro, motivado pelos gritos dos seus pais que subiam da sua opressão no Egito (Ex 2,23-25; Dt 26,7-9). O “novo Israel”, nascido no deserto, faz a sua opção pessoal, sem a qual não poderia entrar e muito menos se manter na terra.

O primeiro passo desse compromisso é "andar no caminho dele". Isto é possível quando se observa as suas ordens (Dt 8,6). A experiência que o povo fez de $\mathrm{YHWH}$, desde a saída do Egito até os limites da terra prometida, testemunha a sua força, grandeza e santidade. Tendo recebido o Decálogo (Ex 20; Dt 5), o povo recebeu a orientação necessária para não se afastar de YHWH, nem para a esquerda nem para a direita, seguindo o caminho da retidão e com os pés longe do mau caminho (Dt 28,14; SI 1; Pr 4,27). Dessa forma, todo o povo manifesta o seu amor por YHWH (Dt 19,9) que tem, para ele, uma meta: a santidade (Lv 19,2; Dt 28,9). O resultado se traduz na bênção da fecundidade para tudo e todos na terra prometida (Dt 30,16) ${ }^{35}$.

\footnotetext{
${ }^{34}$ A dinâmica do amor, presente na aliança, atesta que as palavras da dupla declaração das partes ocorrem de forma literária, legal e litúrgica. $O$ acordo não apenas é redigido com base na lei, mas vem igualmente celebrado, colocando o povo eleito e YHWH numa relação que ultrapassa a mera ação pactual entre um suserano e seus vassalos. Assim, YHWH e o seu povo se movem numa simbiose histórica, na qual ambos atestam que privilégios e responsabilidades caminham juntos, revelando a interação entre fé, esperança e amor (MILLER, 1990, p. 186; WORK, 2009, p. 232-235; PAGANINI, 2011, p. 367-368).

$35 \mathrm{O}$ que Moisés promulga, enquanto legislador, Js 24,14-15 promulga, ainda que usando imperativos, narrando e complementando pelos verbos familiares: amor, ouvir e servir como um ato de escolha pessoal e familiar. Essa escolha levará à vida e ao bem-estar na terra de Canaã (BRUEGGEMANN, 2001, p. 269).
} 
Da parte do povo, em relação a YHWH, o compromisso é um caminho que se desdobra em quatro ações a serem realizadas. Três se encontram debaixo do mesmo verbo: para observar os seus decretos, as suas ordens e os seus juízos. O ato de observar possui o estrito sentido de "guardar" com seriedade algo ou alguém, porque é precioso e porque, assumido, se torna a regra da própria vida. Em Dt 26,17 se encontra a última vez em que o verbo está na $2^{\mathrm{a}}$ pessoa do masculino singular.

A quarta ação é: escutar a sua voz. Como dito acima, aqui se encontra uma síntese. Escutar a voz de YHWH é, na verdade, obedecer à vontade de YHWH que está expressa nas cláusulas da aliança. A voz de YHWH é singularmente escutada na obediência. Pode-se evocar, aqui, Gn 2,4b-3,24. Os progenitores receberam de seu Criador a ordem de não comer do fruto da árvore do conhecimento do bem e do mal, do contrário experimentariam a morte. Fica claro, nesse exemplo, o sentido de escutar a voz de YHWH como obediência. Esta não aconteceu porque ouviram a voz do astuto tentador e se deixaram enganar. Pelo uso desse exemplo, pode-se, de alguma forma, aproximar a Torah à árvore do conhecimento do bem e do mal. A dinâmica é a mesma, bem como a intenção e os objetivos: escutar a voz de YHWH e praticar a aliança. Estas são duas ações imbricadas e que evocam a mesma realidade que permite viver na presença de $\mathrm{YHWH}$ e no dom da terra: a obediência.

v. 18: Então, hoje, YHWH te declarará: Serás para ele por povo peculiar, conforme falou para ti e para observar todas as suas ordens.

À declaração do povo, no "hoje mesmo" (v. 16), segue a declaração de YHWH também feita no "hoje". Nem ontem nem amanhã, mas é no "hoje" que o povo deve se conformar à vontade de YHWH que, igualmente, assume esse "hoje" como próprio e ao povo como sua propriedade peculiar. Esse "hoje" inaugura uma relação duradoura e amorosa da parte de YHWH. Assim, sobressaem os elementos que envolvem, em reciprocidade, as duas partes que contraem a aliança, falando uma após a outra. 
YHWH, pela eleição, deu ao seu povo a dignidade de falar não como vassalo, mas como um verdadeiro partner ${ }^{36}$. A escolha de YHWH separou o "novo Israel" dentre todos os povos da terra. É a eleição que revela a liberdade e a gratuidade de YHWH manifestar e determinar a sua vontade. Como, por vontade própria, criou todas as coisas, também, por pura eleição, decidiu e quis fazer do "novo Israel", nascido e criado durante o tempo da peregrinação do deserto, a sua pessoal propriedade. Essa posição superior aos outros povos não se dá em nível político, ou militar, mas no nível de revelador da glória de $\mathrm{YHWH}$ diante dos outros povos ${ }^{37}$.

O "novo Israel” não será um povo a mais, dentre tantos povos, mas o seu "povo peculiar". Evoca-se na alusão, "conforme falou para ti”, as citações presentes em Ex 19,5-6 e Dt 7,6; 14,2 (citações praticamente idênticas). A particularidade e a força da declaração se encontram no termo segullâ (ộa) que, fora da Torah, ocorre outras quatro vezes (1Cr 29,3; SI 135,4; Ecl 2,8; MI $3,17)$. Por meio desse termo se indica uma propriedade adquirida pelo preço justo.

Na dinâmica da Torah, porém, segullâ evoca a saída do Egito pelo preço do sangue dos primogênitos (Ex 12,29; 13,15), bem como a determinação de YHWH de manter com vida a nova geração que nasceu e cresceu no deserto. Se a saída dos filhos de Israel do Egito se deu às custas da morte dos primogênitos (Ex 12,29-30; 13,1-16g), a eleição do "novo Israel" se deu por causa do perdão dado diante das infidelidades da geração anterior que recebeu a sentença de morte ( $\mathrm{Nm} \mathrm{14,20-38).}$

Se a primeira declaração ocorreu na chegada dos libertos no Sinai, criando a forte ligação entre o "local" da habitação de YHWH com os que Ele libertou, no livro de Deuteronômio, a ligação é estabelecida com o "novo

\footnotetext{
36 Nota-se o estilo típico dos tratados de vassalagem do Antigo Oriente Próximo (LOHFINK, 1968, p. 119-123; AZCÁRATE, 2009, p. 242-243; PAGANINI, 2011, p. 367).

${ }^{37} \mathrm{Na}$ observância de todas as ordens, o povo manifesta a glória de YHWH e endossa o seu status peculiar em relação aos outros povos, pois a santidade é sua relacional consagração que advém da vontade de YHWH, como expressa em Dt 28,9 (CHOLEWINSKI, 1979, p. 122-123; PATRICK, 2008, p. 196; PAGANINI, 2011, p. 367).
} 
Israel" que não está no sopé do Sinai ${ }^{38}$, mas nas estepes de Moab e em breve marchará para a terra de Canaã sob a condução de Josué que figura como lugar-tenente da Torah, homem de valor por sua obediência incondicional à vontade de YHWH (Js 1,1-9).

v. 19: O Altíssimo te colocará sobre todas as gentes que fez, para o louvor, para o nome e para o esplendor e tu há de ser um povo santo para $\mathrm{YHWH}$, teu Deus, conforme falou.

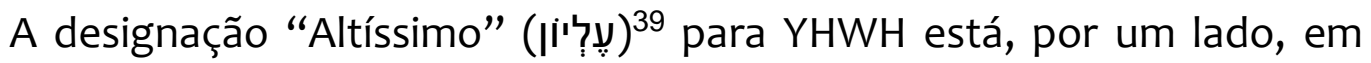
estreita relação com a elevação do "novo Israel", e, por outro lado, serve para demonstrar a grandeza de YHWH sobre as divindades cananeias, visto

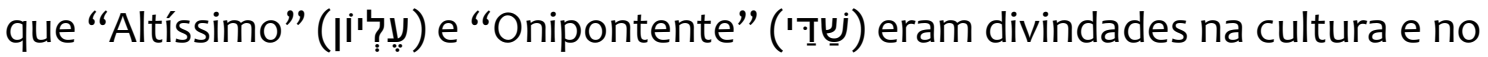
panteão cananeu.

Com isso, cria-se uma simbiose entre o adjetivo usado para qualificar YHWH e o ranque que o povo eleito deverá ocupar, no tocante aos demais povos, em particular os cananeus, quando colocados abaixo do "novo Israel" pelo uso da preposição "sobre" (עַ) e que se encontra dentro do adjetivo "Altíssimo" (עִלְליון).

Apesar de todos os povos serem obra de $\mathrm{YHWH}$, existe um diferencial sendo estabelecido, pois como o ser humano, na ordem da criação, foi elevado acima de todas as criaturas ( $G n$ 1,28), de igual modo, o povo eleito está sendo elevado acima dos demais povos. Tal designação serve para enfatizar o domínio universal de $\mathrm{YHWH}$, claramente indicado na afirmação: "sobre todas as gentes que fez".

De particular importância para o referencial acima aludido, encontra-se o uso do verbo "fazer" (עָשָׁ), atribuído a YHWH, pelo qual se afirma como os demais povos vieram à existência. Tal fato aproxima Dt 26,19 aos relatos da criação, nos quais o verbo é empregado onze vezes em Gn 1,1-2,4a; e uma vez

\footnotetext{
${ }^{38}$ No livro de Deuteronômio, a única alusão ao Sinai ocorre em Dt 33,2, pois preferiu o Horeb para designar o monte de Deus, citado apenas nove vezes (Dt 1,2.6.19; 4,10.15; 5,2; 9,8; 18,16; 28,69).

39 O adjetivo "altíssimo" (עִלְליון) ocorre dez vezes na Torah, mas de maneira significativa, como qualidade divina, aparece no encontro de Abraão com Melquisedeq (Gn 14,18-20.22), no quarto oráculo de Balaão ( $\mathrm{Nm}$ 24,16), e na relação entre o povo eleito e os demais povos (Dt 26,19; $28,1)$, visto que todos estão submetidos à ação de YHWH (Dt 32,8).
} 
em Gn 2,18 quando YHWH decide "fazer" a mulher: o ser semelhante e complementar para o homem.

A finalidade da elevação do povo eleito sobre os demais povos não indica que estes deverão ser submissos àquele. Na verdade, se indica o objetivo: "para o louvor, para o nome e para a exaltação". O “novo Israel”, por ser propriedade peculiar de $\mathrm{YHWH}$, carrega em si a grandeza do seu Deus.

Nos profetas ${ }^{40}$, esta mesma tríade encontra-se como queixa em Jr 13,11: Israel deveria glorificar o seu Deus, mas foi infiel e, em contrapartida, o ridicularizou diante dos demais povos. Encontra-se de forma positiva em Jr 33,9: YHWH anuncia que, após a punição, devolverá a glória de Jerusalém. Pela ótica do Trito Isaías, o povo eleito, após o exílio, será vingado e Jerusalém será coroada de justiça (Is 62,1-12).

É possível entrever a ligação entre Dt 26,19 com Dt 7,6; 14,2.21 à luz do que se diz em Gn 12,3, mas também deve ser lido à luz de Ex 24 e Js 24. Nesse sentido, bênção e aliança são realidades muito próximas e são a base para a categorização do "novo Israel" como povo devotado à vida de santidade, a exemplo do seu Deus (Lv 19,2). Assim, a glória do povo reside na fidelidade à aliança e, por esta, YHWH é glorificado, manifestando no seu povo a sua escolha e consagração.

\section{Considerações finais}

O “hoje mesmo", que permitiu Moisés interpelar o "novo Israel" (v. 16), permite que, igualmente, cada futura geração seja interpelada na sua fé em YHWH. Há uma continuidade entre os que herdarão a terra e os que nela nascerão. Um elemento permanece estável: a ação de YHWH a favor do seu povo é justiça e misericórdia.

O mundo atual está marcado por uma profunda mudança de época que, dentre tantas seduções, tem impulsionado o ser humano a buscar a

\footnotetext{
${ }^{40}$ A novidade na aliança está enraizada no amor incondicional que YHWH tem pelo seu povo. Esta novidade, expressa pelos profetas, vai além da dura condicionalidade que se encontra em Dt (BRUEGGMANN, 2001, p. 250).
} 
justiça como mera retribuição a ser aplicada ao culpado que, por sua vez, deve pagar pelo mal que fez. Em contrapartida, a justiça bíblica não é apenas retribuidora, mas é, acima de tudo, restauradora e reparadora tanto para a parte ofendida, como para a parte ofensora.

Nesse sentido, o "hoje" do povo (v. 17) e o "hoje" de YHWH (v. 18) não perdem valor e sentido, mas continuam sendo as marcas de um tempo favorável e oportuno (kairós), para que se possa propor a mensagem bíblica nos moldes da aliança entre o ser humano, desejoso de bem, justiça, verdade e felicidade, e YHWH que, pela mensagem bíblica, é o maior interessado em realizar o ser humano em plenitude.

Por certo, cabe, primeiramente, aos que se dizem crentes e seguidores da Bíblia e da sua mensagem, dar o testemunho convincente de que os seus textos não são fósseis do passado, mas possuem "hoje" o frescor capaz de dar ao ser humano a verdade que restaura e liberta de todas as formas de opressão e violência.

Cada época tem seus desafios e exigências que devem ser enfrentados não apenas com o avanço da ciência e da tecnologia, mas com todos os meios e formas necessários para tornar o ser humano mais atento à realidade e, principalmente, ao seu próximo que vive na indigência e no sofrimento causados por tantas injustiças sociais e eclesiais que exigem uma justa reparação.

Se o "novo Israel" de Dt 26,16-19 foi eleito por YHWH e colocado acima dos outros povos, o "novo Israel", de cada época e lugar, existe para demonstrar o seu amor a YHWH, através do serviço obediencial à sua vontade, pelo qual alcançará a felicidade não apenas para si, mas para toda a humanidade. Permanece, para "hoje" e sempre, a máxima: "Não te deixes vencer pelo mal, mas vence com o bem o mal!" (Rm 12,21).

\section{Referências}

AZCÁRATE, J. L. de L. Deuteronomio (Comentários a la Nueva Bíblia de Jerusalém). España: Desclée De Brouwer, 2009.

BRAULIK, G. Deuteronomio. Il testamento di Mosè. Assisi: Cittadella editrice, 1987. 
BRUEGGEMANN, W. Deuteronomy. Nashiville: Abingdon, 2001.

CAIRNS, I. Deuteronomy. Word and Presence. Michigan: Eerdmans Publishing Company, 1992.

CHRISTENSEN, D. L. Deuteronomy 21:10-34,12. Nashville: Thomas Nelson Publishers, 2002.

CLIFFORD, R. Deuteronomio con un excursus su Alleanza e Legge. Brescia: Queriniana, 1995.

DA SILVA, A. J. “A história de Israel na pesquisa atual”. In: FARIA, J. de F. (org.). História de Israel e as pesquisas recentes. Petrópolis/RJ: Vozes, 2003.

DeVRIES, S. J. "The Development of the Deuteronomic Promulgation Formula". Biblica 55, p. 301-316, 1974.

GARCÍA LÓPEZ, F. Deuteronomio. Texto y Comentario. Salamanca: Sigueme, 1992.

HOPPE, L. Deuteronomio. Brescia: Queriniana, 1993.

KESSLER, R. História Social do Antigo Israel. São Paulo: Paulinas, 2009.

LOHFINK, N. “Lectures in Deuteronomy”. Rome: PIB, 1968.

LOHFINK, N. "Dt 26,17-19 und die 'Bundesformel”'. In: LOHFINK, N. (ed). Studien zum Deuteronomium und zur deuteronomistischen Literatur I. Stuttgart: Verlag Katholisches Bibelwerk GmbH, 1990. p. 211-261.

LUNDBOM, J. R. Deuteronomy. A Commentary. Grand Rapids, Michigan: Willian B. Eerdmans Publishing Company, 2013.

MANN, T. W. Deuteronomy. Louisville, Kentucky: Westminster John Knox Press, 1995.

MAXWELL, J. Mastering the Old Testament: Deuteronomy. Dallas-LondonVancouver-Melbourne: World Publishing, 1987.

MAZZINGHI, L. História de Israel - Das origens ao período romano. Petrópolis/RJ: Vozes, 2017.

MILLER, P. D. Deuteronômio. Torino: Claudiana, 2008.

NELSON, R. D. Deuteronomy. A Commentary. Louisville-London: Westminster John Knox Press, 2002.

PAGANINI, S. Deuteronomio: nuova versione, introduzione e commento. Milano: Paoline, 2011. 
PAPOLA, G. Deuteronomio. Introduzione, traduzione e commento. Cinisello Balsamo: San Paolo, 2011.

RÖMER, T. A chamada história Deutoronomista: Introdução sociológica, histórica e literária. Trad. G. A. Titton. Petrópolis: Vozes, 2008.

SONNET, J.-P. «Ce jour-là», «jusqu'à ce jour»: L'arc de la communication narrative dans la Bible hébraïque. (Version originale française de l'article à paraître dans la Rivista liturgica (2018): “"In quel giorno", "Fino a questo giorno": L'arco della comunicazione narrativa nella Bibbia ebraica»). Disponível em: <www.academia.edu>. Acesso em: 17 set. 2018.

STRONG, J. Dicionário bíblico Strong (Léxico hebraico, aramaico e grego). São Paulo: Sociedade Bíblica do Brasil, 2002.

THOMPSON, J. A. Deuteronomy. An introduction and commentary. Leicester, London: Inter-Varsity Press, 1974.

WORK, T. Deuteronomy. Grand Rapids, Michigan: Brazos Press, 2009.

WRIGHT, C. J. H. Deuteronomy. Peabody, Massachusetts: Hendrickson Publishers/paternoster press, 1996.

VON RAD, G. Deuteronomio. Brescia: Paideia, 1979. 